\title{
MicroRNA-214 promotes the proliferation, migration and invasion of gastric cancer MKN28 cells by suppressing the expression of Dact2
}

\author{
LEI ZHAO ${ }^{1}$, WEIWEI FAN ${ }^{2}$, YUJING FAN ${ }^{1}$ and SHANLING GAO ${ }^{1}$ \\ ${ }^{1}$ Department of Gastroenterology, The Second Affiliated Hospital of Harbin Medical University, Harbin, Heilongjiang 150086; \\ ${ }^{2}$ Department of Infectious Internal Medicine, Heilongjiang Provincial Hospital, Harbin, Heilongjiang 150036, P.R. China
}

Received August 5, 2017; Accepted September 7, 2018

DOI: 10.3892/etm.2018.6771

\begin{abstract}
The present study examined the expression of Dapper, antagonist of $\beta$-catenin 2 (Dact2) and microRNA (miR)-214 in gastric cancer at tissue and cellular levels, and to understand their biological roles. A total of 42 gastric cancer patients were enrolled in the present study. Bioinformatics tool was used to predict the miR molecule that potentially regulates Dact 2 expression. To measure the expression of miR-214 and Dact2, reverse transcription-quantitative polymerase chain reaction was employed. Mixed gastric adenocarcinoma type MKN28 cells were transfected with negative control (NC), miR-214 mimics or inhibitor. The CCK-8 assay was used to investigate the proliferation of mixed gastric adenocarcinoma type MKN28 cells. To study migration and invasion abilities of mixed gastric adenocarcinoma type MKN28 cells, the Transwell assay was performed. To determine the expression of Dact 2 protein, western blotting was conducted and the rescue assay was utilized to study the biological roles of miR-214 and Dact 2 in mixed gastric adenocarcinoma type MKN28 cells. To test whether Dact 2 is a direct target of miR-214, the dual luciferase reporter assay was performed. Results indicated that the expression of miR-214 was elevated, but expression of Dact 2 mRNA was decreased in gastric cancer tissues, which was closely correlated with the invasion, metastasis, occurrence and development of gastric cancer. Notably, miR-214 promoted the proliferation of mixed gastric adenocarcinoma type MKN28 cells in vitro, whereas but Dact2 inhibited the proliferation of these cells. Downregulation of miR-214 expression or upregulation of Dact 2 expression inhibited the migration and invasion of mixed gastric adenocarcinoma type MKN28 cells. Furthermore, miR-214 regulated the expression of Dact 2 protein and its downstream $\beta$-catenin protein
\end{abstract}

Correspondence to: Dr Lei Zhao, Department of Gastroenterology, The Second Affiliated Hospital of Harbin Medical University, 246 Xuefu Road, Harbin, Heilongjiang 150086, P.R. China

E-mail: 18989131890@163.com

Key words: microRNA-214, Dact2, gastric cancer in mixed gastric adenocarcinoma type MKN28 cells. Dact2 reversed the effect of miR-214 on the proliferation, migration and invasion of mixed gastric adenocarcinoma type MKN28 cells. In addition, miR-214 directly targeted the 3'-UTR seeding region of Dact 2 mRNA to regulate its expression. The present study demonstrated that expression of miR-214 was upregulated in gastric cancer tissues, and positively correlated with lymphatic metastasis and clinical staging. In addition, expression of Dact 2 was downregulated in gastric cancer tissues and negatively correlated with lymphatic metastasis and clinical staging. Notably, the present findings suggest that miR-214 promoted the proliferation, migration and invasion of mixed gastric adenocarcinoma type MKN28 cells by suppressing the expression of Dact2.

\section{Introduction}

Gastric cancer is the most common malignant tumor of digestive tract, and its morbidity and mortality are the second highest in all malignant tumors in the world (1-3). After clinical treatments, the five-year survival rate of patients with early gastric cancer can reach $98 \%$, but patients with advanced gastric cancer have poor prognosis due to distant metastasis (4). Tumor recurrence and metastasis are the major causes of death in patients with gastric cancer (5). Because the early symptoms of gastric cancer are not obvious and the disease lack of specific diagnostic markers, most patients are in the middle and late stage of gastric cancer at diagnosis, and postoperative recurrence and metastasis are easy to occur (6). Therefore, researches on the molecular mechanism of recurrence and metastasis of gastric cancer is of great significance for its clinical diagnosis and treatment.

Dapper, antagonist of $\beta$-catenin (Dact) gene is a signal pathway regulating molecule that exerts its function by negatively regulating $\mathrm{Wnt} / \beta$-catenin and Nodal/TGF $\beta$ signaling pathways $(7,8)$. Wnt/ $\beta$-catenin and Nodal/TGF $\beta$ signaling pathways participate in the regulation of the occurrence and development of tumors, and Dact gene can therefore play a role in the occurrence and development of tumors by affecting these signaling pathways (9). Dact2 gene is a member of Dact family that plays a role in tumors by participating in the negative regulation of both Wnt/ $\beta$-catenin and Nodal/TGF $\beta$ 
signaling pathways (10). As a tumor-suppressor gene in esophageal cancer, liver cancer, and lymphoma, Dact 2 inhibits the occurrence and development of tumors by regulating the methylation of gene promoters (11-13). However, it is still unknown whether Dact 2 is regulated by other factors. A study on the methylation in hepatocellular carcinoma and gastric cancer tissues shows that promoter methylation is not found in some patients with low expression of Dact2 (14), suggesting that Dact 2 may be regulated by other factors.

MicroRNA (miRNA or miR) is a class of small non-encoding RNA molecules (18-22 nucleotides) that bind with the 3'-untranslated region (UTR) of mRNA to inhibit its translation (15). miRNA plays important regulatory roles in post-transcriptional levels of genes, and widely participates in the proliferation, aging, apoptosis, migration, differentiation, and drug resistance of cells (16). Studies show that the expression of a variety of miRNA molecules is abnormal in gastric cancer, and closely related with the occurrence and development of the disease. For example, miR-1 and miR-200c act as tumor-suppressor genes in gastric cancer, and the downregulation of their expression promotes the migration of gastric cancer cells $(17,18)$. In addition, miR-33b-5p enhances the sensitivity of gastric cancer cells to chemotherapeutic drugs and improves their clinical efficacy (19). Of note, Wnt/ $\beta$-catenin signaling pathway that is regulated by Dact2, is also regulated by various miRNA molecules (20). Therefore, miRNA is likely to be involved in the regulation of Dact 2 gene. In the present study, we investigate the miRNA molecule that regulates Dact2 gene at tissue and cellular levels, and try to elucidate the mechanism of action of the miRNA molecule.

\section{Patients and methods}

Bioinformatics. Using miRNA molecule online prediction software Targetscan 7.1 (www.targetscan.org/vert_71/), we predicted the miRNA molecules that might regulate the expression of Dact2 gene following the instructions on the website.

Patients. A total of 42 patients who received surgical resection of gastric cancer tissues at our hospital between December 2014 and February 2016 were included in the present study (Table I). The 42 cases of resected gastric cancer tissues were sliced and stained with hematoxylin and eosin, and examined by two pathologists independently. Patients with lymphatic metastasis were included into N1 group, while those without lymphatic metastasis were included into N0 group. According to 2003 WHO cancer classification criteria, 17 cases were included into stage I, 12 cases were included into stage II, 10 cases were included into stage III, and 3 cases were included into stage IV. Among all 42 patients, 31 patients had moderate or high differentiation, and 11 patients had low differentiation. Tumor-adjacent tissues $5 \mathrm{~cm}$ away from tumor tissues were also collected as controls. The tissue samples were frozen in liquid nitrogen and stored at $-80^{\circ} \mathrm{C}$. Clinical information and pathological data of the patients were collected. All procedures were approved by the Ethics Committee of Harbin Medical University. Written informed consents were obtained from all patients or their families.
Table I. The clinic characteristics of 42 gastric cancer patients.

\begin{tabular}{lc}
\hline Indexes & Number of patients \\
\hline Sex & 27 \\
Male & 15 \\
Female & \\
Age (year) & 26 \\
$\leq 60$ & 16 \\
$\geq 60$ & \\
Tumor size (cm) & 30 \\
$\leq 5$ & 12 \\
$\geq 5$ & \\
TNM stages & 17 \\
I & 12 \\
II & 10 \\
III & 3 \\
IV & \\
Differentiation & 16 \\
Well & 15 \\
Moderate & 11 \\
Poor & \\
Lymphatic metastasis & 23 \\
Yes & \\
No & \\
\hline & \\
& \\
&
\end{tabular}

Cells. Mixed gastric adenocarcinoma type Gastric cancer MKN28 line was a derivative of MKN74 cells (which are also a gastric adenocarcinoma cell line) (21). was cultured in RPMI-1640 medium supplemented with $10 \%$ fetal bovine serum (FBS) at $37^{\circ} \mathrm{C}$ and $5 \% \mathrm{CO}_{2}$. When reaching $80-90 \%$ confluency, the cells were passaged. The medium was replaced every two days. Cells with passage numbers 3-6 were used for experiments.

Mixed gastric adenocarcinoma type MKN28 cells were divided into negative control (NC) group, miR-214 mimics group and miR-214 inhibitor group. On the day before transfection, mixed gastric adenocarcinoma type MKN28 cells $\left(2 \times 10^{5}\right)$ in log-phase growth were seeded onto 24 -well plates containing antibiotics-free RPMI-1640 medium supplemented with $10 \%$ FBS. When reaching $70 \%$ confluency, $1.5 \mu 1 \mathrm{miR}-214$ mimics/inhibitor (20 pmol $/ \mu \mathrm{l}$; RiboBio, Guangzhou, China) and $1 \mu \mathrm{l}$ Lipofectamine 2000 (Thermo Fisher Scientific, Inc., Waltham, MA, USA) were added into two individual vials containing $50 \mu \mathrm{l}$ Opti Memi medium, respectively. Five min later, the liquids in the two vials were mixed together before standing still for another $20 \mathrm{~min}$. Then, the mixture was added onto the cells for an incubation of $6 \mathrm{~h}$ before changing to RPMI-1640 medium supplemented with 10\% FBS. The cells were cultured at $37^{\circ} \mathrm{C}$ and $5 \% \mathrm{CO}_{2}$ for $48 \mathrm{~h}$ before use.

For rescue experiments, mixed gastric adenocarcinoma type MKN28 cells $\left(2 \times 10^{5}\right)$ in miR-NC and miR-214 inhibitor groups were seeded into 24-well plates containing antibiotics-free RPMI-1640 medium supplemented with $10 \%$ FBS. When reaching $60 \%$ confluency, mixed gastric adenocarcinoma type MKN28 cells in miR-214 inhibitor group were 
infected by sh-DACT2 plasmid (Hanbio Biotechnology Co., Ltd., Shanghai, China), while cells in miR-NC group were infected by $0.5 \mu \mathrm{g} \mathrm{NC}$ plasmid. After being cultured at $37^{\circ} \mathrm{C}$ and under $5 \% \mathrm{CO}_{2}$ for $6 \mathrm{~h}$, the medium was refreshed to newly made RPMI-1640 medium containing 10\% FBS before cultivation for $72 \mathrm{~h}$. Then, RPMI-1640 medium containing $1 \mu \mathrm{g} / \mathrm{ml}$ puro was added before incubation for $72 \mathrm{~h}$.

Quantitative real-time polymerase chain reaction ( $q R T-P C R$ ). Gastric cancer and tumor-adjacent tissues (100 mg) were ground into powder using liquid nitrogen before addition of $1 \mathrm{ml}$ TRIzol isolation reagent (Thermo Fisher Scientific, Inc.) for lysis. After lysis, total RNA was extracted using phenol chloroform method. The purity of RNA was determined by A260/A280 using ultraviolet spectrophotometry (Nanodrop ND2000; Thermo Scientific, Inc.). Then, cDNA was obtained by reverse transcription using miScript II RT kit (Qiagen, Hilden, Germany) from $1 \mu \mathrm{g}$ RNA and stored at $-20^{\circ} \mathrm{C}$.

qRT-PCR was performed using miScript SYBR ${ }^{\circledR}$ Green PCR kit (Qiagen) and the reaction system was composed of $10 \mu \mathrm{l}$ qRT-PCR-Mix, $0.5 \mu \mathrm{l}$ upstream primer (5'-ACAGCA GGCACAGACAGGCAGT-3'), $0.5 \mu 1$ downstream primer (universal primer provided by the kit), $2 \mu \mathrm{l}$ cDNA and $7 \mu \mathrm{l}$ $\mathrm{ddH}_{2} \mathrm{O}$. Reaction protocol was initial denaturation at $95^{\circ} \mathrm{C}$ for $10 \mathrm{~min}$, and 40 cycles of $95^{\circ} \mathrm{C}$ for $1 \mathrm{~min}$ and $60^{\circ} \mathrm{C}$ for $30 \mathrm{sec}$.

Cell-Counting kit (CCK)- 8 assay. The sample cells were inoculated in 96-well plates at a density of 2,000/well. At 0, 24, 48 and 72 h, $20 \mu \mathrm{l} \mathrm{CCK-8} \mathrm{(5} \mathrm{g/l;} \mathrm{Beyotime} \mathrm{Institute}$ of Biotechnology, Beijing, China) was added onto the cells. After being incubated at $37^{\circ} \mathrm{C}$ for $2 \mathrm{~h}$, absorbance $(490 \mathrm{~nm})$ of each well was determined, and cell proliferation curves were plotted. Each group was tested in 3 replicate wells and the values were averaged.

Transwell assay. Matrigel chambers (Corning Inc., Corning, NY, USA) were used to determine the migration and invasion abilities of cells. Matrigel was first diluted with serum-free RPMI-1640 medium at a ratio of 1:2. In upper chamber, $50 \mu \mathrm{l}$ diluted Matrigel was added and kept at $37^{\circ} \mathrm{C}$ for $1 \mathrm{~h}$. Then, $1 \times 10^{5}$ cells and $200 \mu \mathrm{l}$ serum-free RPMI-1640 medium were added into the upper chamber. In the lower chamber, $500 \mu \mathrm{l}$ RPMI-1640 medium supplemented with $10 \%$ FBS was added. After incubation for $24 \mathrm{~h}$, the cells in upper chamber were wiped by cotton swab. Then, the chamber was fixed using $4 \%$ formaldehyde for $10 \mathrm{~min}$ at room temperature, and then subjected to Giemsa's staining for $1 \mathrm{~min}$. After washing for 3 times, cells that moved to the other side of the chamber were counted under a microscope (5 fields; magnification, x200) to evaluate migration and invasion abilities.

Western blot analysis. Cells in each group were trypsinized and collected. Then, cold Radio-Immunoprecipitation Assay (RIPA) lysis buffer (600 $\mu \mathrm{l}$; Beyotime Institute of Biotechnology) was mixed with the samples. Then, the mixture was lysed for $30 \mathrm{~min}$ on ice, and then centrifuged at $12,000 \mathrm{rpm}$ and $4^{\circ} \mathrm{C}$ for $10 \mathrm{~min}$. Bicinchoninic acid (BCA) protein concentration determination kit (RTP7102; Real-Times Biotechnology Co., Ltd., Beijing, China) was used to determine protein concentration in the supernatant. After mixing protein samples $(6 \mu 1)$ with $5 \mathrm{X}$ sodium dodecyl sulfate loading buffer, the mixture was denatured by boiling in water bath for $10 \mathrm{~min}$. Afterwards, $10 \%$ sodium dodecyl sulfate-polyacrylamide gel electrophoresis (100 V) was performed using the samples. Then, the proteins were electro-transferred to polyvinylidene difluoride (PVDF) membranes on ice ( $250 \mathrm{~mA}, 1 \mathrm{~h})$ before being blocked with $50 \mathrm{~g} / \mathrm{l}$ skimmed milk at room temperature for $1 \mathrm{~h}$. Afterwards, rabbit anti-human $\beta$-catenin and DACT2 polyclonal primary antibodies (both 1:1,000) and mouse anti-human GAPDH primary antibody (1:4,000; both Abcam, Cambridge, UK) were added onto the membranes before incubation at $4^{\circ} \mathrm{C}$ overnight. Then, the membrane was extensively washed with phosphate-buffered saline with Tween-20 (PBST) for 5 times of $5 \mathrm{~min}$, and incubated with goat anti-mouse horseradish peroxidase-conjugated secondary antibodies $(1: 4,000$; Abcam) at room temperature for $1 \mathrm{~h}$. Subsequently, the membrane was washed with PBST for 5 times of $5 \mathrm{~min}$ before the membrane was developed with enhanced chemiluminescence detection kit (Sigma-Aldrich; Merck KGaA, Darmstadt, Germany) for imaging. We used Image lab v3.0 software (Bio-Rad Laboratories, Inc., Hercules, CA, USA) to acquire and analyze imaging data. The relative expression of target proteins was expressed with the ratio against GAPDH.

Dual luciferase reporter assay. Wild-type (WT) and mutant seeding regions of miR-214 in 3'-UTR of DACT2 gene were chemically synthesized before adding Spe-1 and HindIII restriction sites, and then cloned into pMIR-REPORT luciferase reporter plasmids $(0.5 \mu \mathrm{g})$ with WT or mutant 3'-UTR DNA sequences, which were transfected together with miR-214 mimics into HEK293T cells. Following incubation for $24 \mathrm{~h}$, cells were processed using dual luciferase reporter assay kit according to the manufacturer's manual (Beyotime Institute of Biotechnology), and fluorescence intensity was determined by GloMax 20/20 luminometer (Promega, Fitchburg, WI, USA). Fluorescence values of each group of were measured using renilla fluorescence activity as internal reference.

Statistical analysis. All results were analyzed using SPSS 17.0 statistical software (SPSS, Inc., Chicago, IL, USA), and all data were shown as means \pm SD. Comparison between groups was performed using group t-test. The results among multiple groups were compared using one-way analysis of variance followed by Dunnett's test as the post hoc test. $\mathrm{P}<0.05$ was considered to indicate a statistically significant difference.

\section{Results}

Expression of miR-214 is elevated, but expression of Dact 2 mRNA is decreased in gastric cancer tissues, being closely correlated with the invasion, metastasis, occurrence and development of gastric cancer. To search miRNA molecules that might participate in the regulation of Dact 2 gene, Targetscan 7.1 website was used. Search of Dact 2 on the website showed that miR-214 was likely to be involved in the regulation of Dact2 expression (Fig. 1). To further test the expression of miR-214 and Dact 2 in gastric cancer, qRT-PCR was performed. The data showed that expression of miR-214 
hsa-miR-214-3p
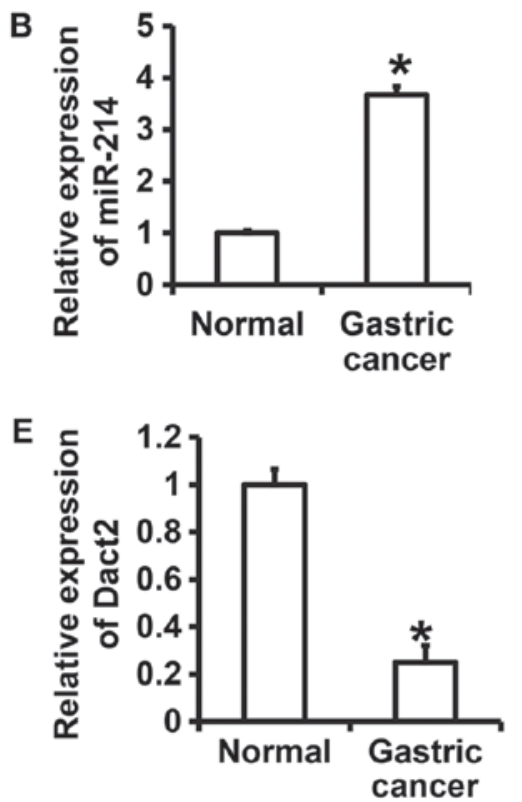
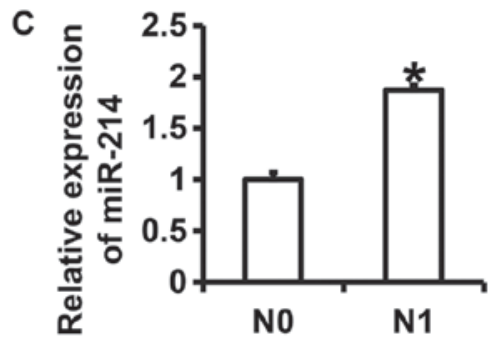

$\mathbf{F}$

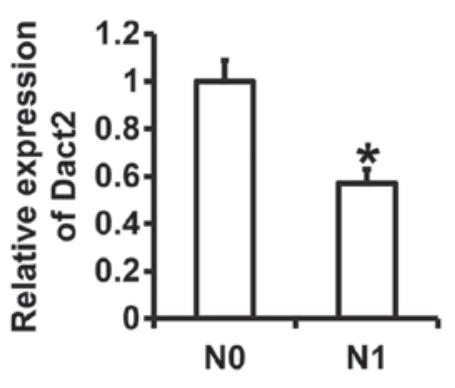

\section{| || || | |}

3' UGACGGACAGACACGGACGACA
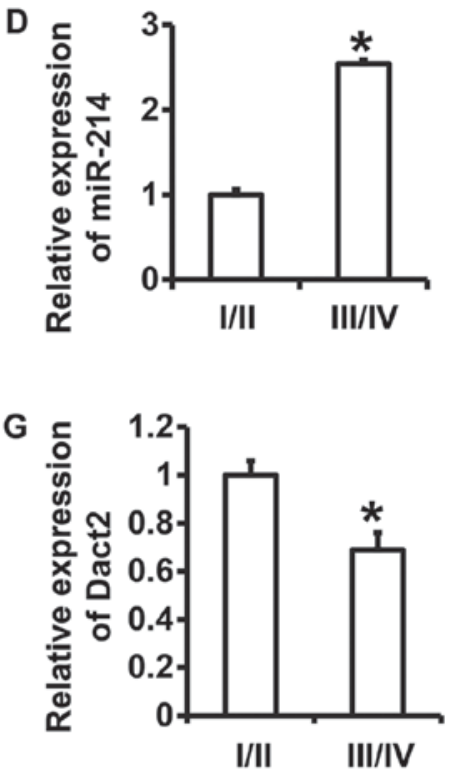

Figure 1. Prediction of interaction between miR-214 and Dact2, and the expression of miR-214 and Dact2 mRNA in gastric cancer tissues. (A) Bioinformatics prediction of miRNA molecule that regulates the expression of Dact2 gene using miRNA molecule online prediction software Targetscan 7.1 (www.targetscan. org/vert_71/). (B-D) Expression of miR-214 in (B) tumor-adjacent normal tissues and gastric cancer tissues ( $\mathrm{P}<0.05$ compared with normal group), (C) patients without (N0)/with (N1) lymphatic metastasis ( ${ }^{*} \mathrm{P}<0.05$ compared with N0 group), and (D) patients at clinical stages I/II or III/IV (* $<0.05$ compared with I/II group). (E-G) Expression of Dact 2 mRNA in (E) tumor-adjacent normal tissues and gastric cancer tissues ("P<0.05 compared with normal group), (F) patients without (N0)/with (N1) lymphatic metastasis ( ${ }^{*} \mathrm{P}<0.05$ compared with N0 group), and (G) patients at clinical stages I/II or III/IV ( ${ }^{*} \mathrm{P}<0.05$ compared with I/II group). miRNA, microRNA; Dact2, dapper, antagonist of $\beta$-catenin 2.
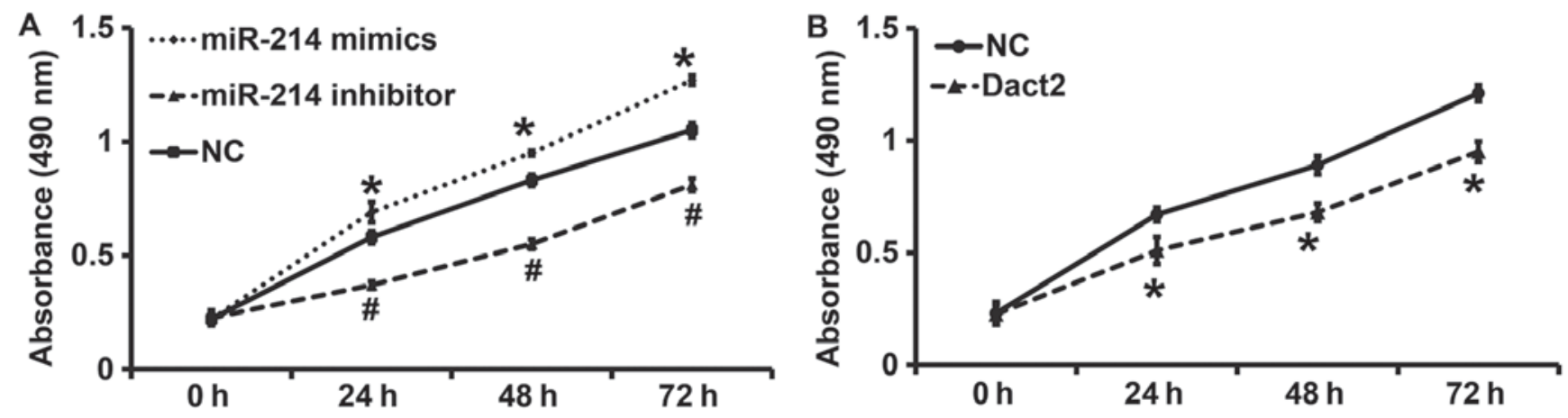

Figure 2. Effect of miR-214 and Dact2 gene on the proliferation of mixed gastric adenocarcinoma type MKN28 cells. CCK-8 assay was used to determine the proliferation of the cells. (A) Mixed gastric adenocarcinoma type MKN28 cells were transfected with NC, miR-214 mimics or miR-214 inhibitor. ${ }^{*} \mathrm{P}<0.05$ compared with NC group; ${ }^{*} \mathrm{P}<0.05$ compared with miR-214 mimics group. (B) Mixed gastric adenocarcinoma type MKN28 cells were transfected with NC or Dact2. "P<0.05 compared with NC group. NC, negative control; miRNA, microRNA; Dact2, dapper, antagonist of $\beta$-catenin 2; CCK-8, Cell-Counting kit.

in gastric cancer tissues was significantly higher than that in tumor-adjacent tissues $(\mathrm{P}<0.05)$ (Fig. 1B). In addition, miR-214 expression in $\mathrm{N} 1$ group was significantly higher than that in N0 group $(\mathrm{P}<0.05)$ (Fig. 1C). Of note, miR-214 expression in gastric cancer tissues from patients at stages III/IV was significantly higher than that from patients at stages I/II $(\mathrm{P}<0.05)$ (Fig. 1D). By contrast, the expression of Dact $2 \mathrm{mRNA}$ in gastric cancer tissues was significantly decreased than that in tumor-adjacent tissues $(\mathrm{P}<0.05)$ (Fig. 1E). The expression of Dact 2 mRNA in gastric cancer tissues in N1 group was significantly lower than that in N0 group $(\mathrm{P}<0.05)($ Fig. $1 \mathrm{~F})$.
Moreover, the expression of Dact 2 mRNA in gastric cancer tissues from patients at stages III/IV was significantly reduced than that from patients at stages I/II $(\mathrm{P}<0.05)$ (Fig. 1G). The results suggest that expression of miR-214 is elevated, but expression of Dact 2 mRNA is decreased in gastric cancer tissues, being closely correlated with the invasion, metastasis, occurrence and development of gastric cancer.

miR-214 promotes, but Dact2 inhibits the proliferation of gastric cancer MKN28 cells in vitro. To examine the proliferation of mixed gastric adenocarcinoma type MKN28 

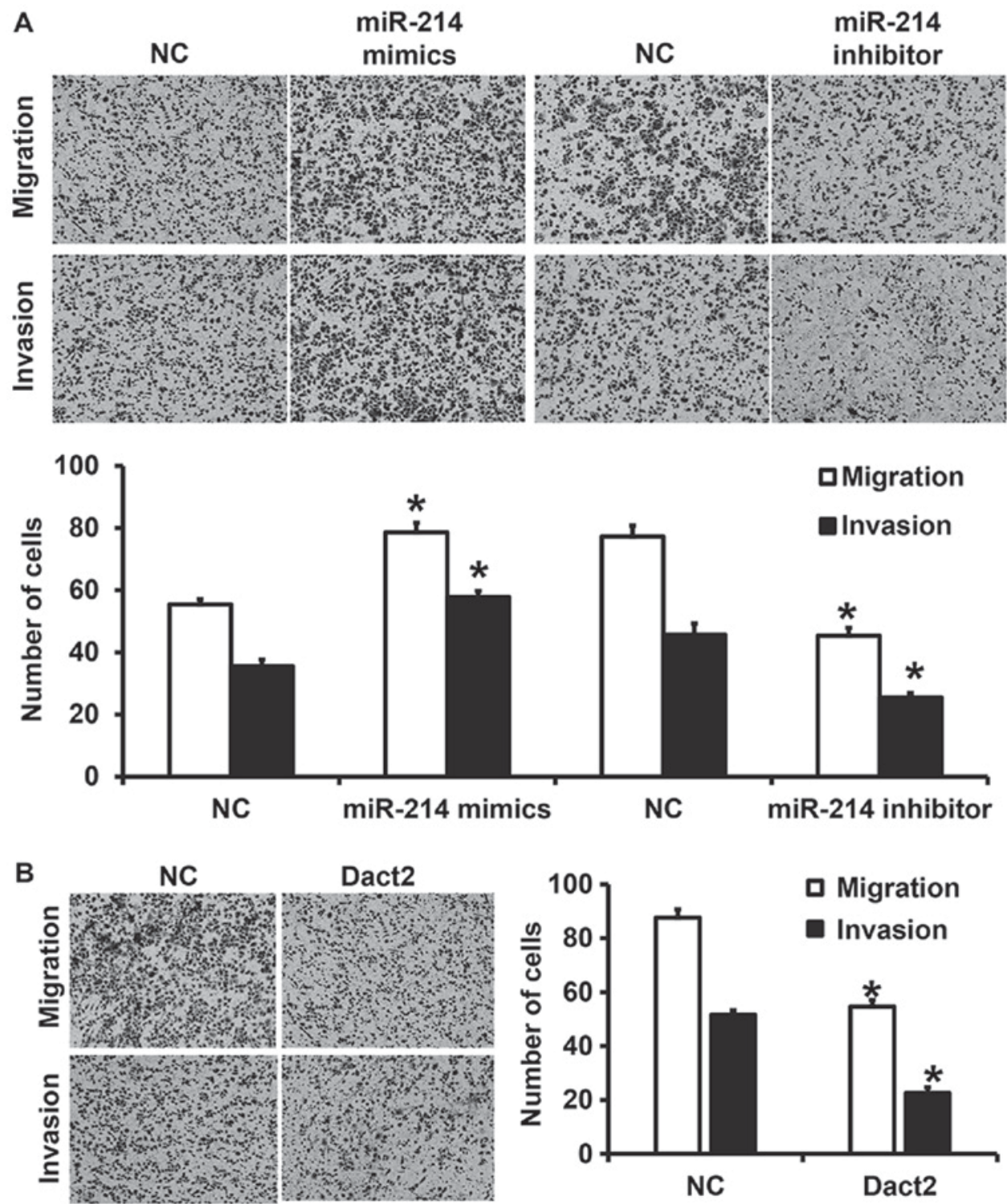

Figure 3. Effect of miR-214 and Dact2 on the migration and invasion of mixed gastric adenocarcinoma type MKN28 cells. (A) Images and number of migrated and invasion cells in indicated groups. Mixed gastric adenocarcinoma type MKN28 cells were transfected with NC, miR-214 mimics or miR-214 inhibitor. (B) Images and number of migrated and invasion cells in indicated groups. Mixed gastric adenocarcinoma type MKN28 cells were transfected with NC or Dact2. Transwell assay was used to determine the migration and invasion of mixed gastric adenocarcinoma type MKN28 cells (magnification, $\mathrm{x} 100)$. ${ }^{*} \mathrm{P}<0.05$ compared with NC group. NC, negative control; miRNA, microRNA; Dact2, dapper, antagonist of $\beta$-catenin 2.

cells, CCK-8 assay was carried out. The data showed that the absorbance of mixed gastric adenocarcinoma type MKN28 cells transfected with miR-214 mimics was significantly higher than that from cells in NC group at all time points $(\mathrm{P}<0.05)$, while the absorbance of the cells transfected with miR-214 inhibitor was significantly lower than that from cells in NC group at all time points $(\mathrm{P}<0.05)($ Fig. $2 \mathrm{~A})$. By contrast, the absorbance of mixed gastric adenocarcinoma type MKN28 cells with overexpression of Dact2 gene was significantly lower than that of cells in NC group at all time points $(\mathrm{P}<0.05)$ (Fig. 2B). The results indicate that miR-214 promotes, but Dact 2 inhibits the proliferation of gastric cancer MKN28 cells in vitro.

Downregulation of miR-214 expression or upregulation of Dact 2 expression inhibits the migration and invasion of mixed gastric adenocarcinoma type MKN28 cells. To investigate migration and invasion abilities of mixed gastric adenocarcinoma type MKN28 cells, Transwell assay was employed. The data showed that the numbers of cells in miR-214 mimics group that crossed chamber membrane in migration and invasion assays were increased than those in NC group $(\mathrm{P}<0.05)$. By contrast, cell counts in miR-214 inhibitor group that crossed chamber membrane in migration and invasion assays were lower than those in NC group $(\mathrm{P}<0.05)$. Similarly, cell count in miR-214 mimics group that crossed chamber membrane in invasion assay was reduced than that in miR-NC group $(\mathrm{P}<0.05)$ (Fig. 3A). Moreover, the numbers of cells in Dact2 group that crossed chamber membrane in migration and invasion assays were significantly reduced compared with those in NC group $(\mathrm{P}<0.05)$ (Fig. 3B). The results suggest that downregulation of miR-214 expression or upregulation of Dact 2 expression inhibits the migration and invasion of mixed gastric adenocarcinoma type MKN28 cells. 
miR-214 regulates the expression of Dact 2 protein and its downstream $\beta$-catenin protein in mixed gastric adenocarcinoma type MKN28 cells. To test Dact2 and $\beta$-catenin protein expression in mixed gastric adenocarcinoma type MKN28 cells, western blotting was performed. Quantification of western blots showed that Dact2 protein expression in miR-214 mimics group was significantly reduced than that in NC group $(\mathrm{P}<0.05)$, while $\beta$-catenin expression in miR-214 mimics group was significantly higher than that in $\mathrm{NC}$ group $(\mathrm{P}<0.05)$. By contrast, Dact2 protein expression in miR-214 inhibitor group was significantly higher than that in $\mathrm{NC}$ group $(\mathrm{P}<0.05)$, while $\beta$-catenin expression in miR-214 inhibitor group was significantly lower than that in NC group $(\mathrm{P}<0.05)$ (Fig. 4A). Moreover, transfection with Dact2 plasmid significantly elevated Dact2 expression in mixed gastric adenocarcinoma type MKN28 cells $(\mathrm{P}<0.05)$, but significantly reduced $\beta$-catenin expression $(\mathrm{P}<0.05)$ (Fig. 4B). The results indicate that miR-214 regulates the expression of Dact2 protein and its downstream $\beta$-catenin protein in mixed gastric adenocarcinoma type MKN28 cells.

Dact 2 reverses the effect of $m i R-214$ on the proliferation, migration and invasion of gastric cancer MKN28 cells. To test how the regulation of Dact 2 by miR-214 affects biological functions of mixed gastric adenocarcinoma type MKN28 cells, we silenced and rescued the expression of miR-214. Western blotting showed that Dact2 expression in miR-214 inhibitor group was significantly higher than that in $\mathrm{NC}$ group $(\mathrm{P}<0.05)$, while that in rescue group was significantly lower than that in miR-214 inhibitor group $(\mathrm{P}<0.05)$ (Fig. 5A). CCK-8 assay showed that the absorbance of cells in miR-214 inhibitor group was significantly reduced than that in $\mathrm{NC}$ group at all time points $(\mathrm{P}<0.05)$, while that in rescue group was significantly higher than that in miR-214 inhibitor group at all time points $(\mathrm{P}<0.05)$, reaching a level similar to NC group (Fig. 5B). Moreover, Transwell assay showed that the numbers of cells in miR-214 inhibitor group that crossed chamber membrane in migration and invasion assays were significantly lower than those in $\mathrm{NC}$ group, respectively $(\mathrm{P}<0.05)$, while those in rescue group were significantly higher than those in miR-214 inhibitor group $(\mathrm{P}<0.05)$ (Fig. 5C). The results suggest that Dact2 reverses the effect of miR-214 on the proliferation, migration and invasion of mixed gastric adenocarcinoma type MKN28 cells.

miR-214 can bind with the 3 '-UTR seeding region of Dact 2 mRNA to regulate its expression. To identify the interaction between miR-214 and the 3'-UTR of Dact2 mRNA, dual luciferase reporter assay was performed. The fluorescence value of cells co-transfected with miR-214 mimics and pMIR-REPORT-WT luciferase reporter plasmids was significantly lower than that in $\mathrm{NC}$ group $(\mathrm{P}<0.05)$. By contrast, the fluorescence value of cells co-transfected with miR-214 mimics and pMIR-REPORT-mutant luciferase reporter plasmids was not significantly different from that in NC group ( $\mathrm{P}>0.05)$ (Fig. 6). The result indicates that miR-214 can bind with the 3'-UTR seeding region of Dact2 mRNA to regulate its expression.

\section{Discussion}

Gastric cancer is a systemic disease, and its recurrence and metastasis are the major causes of poor prognosis (4). Similar
A
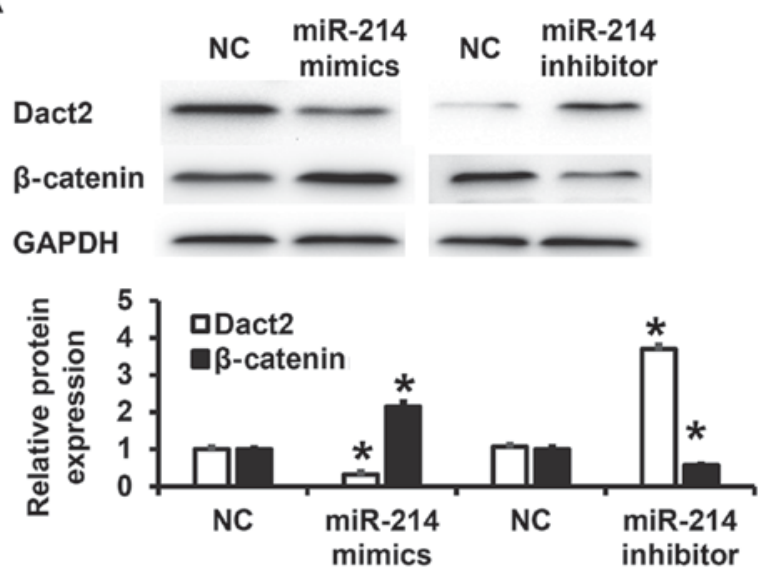

B

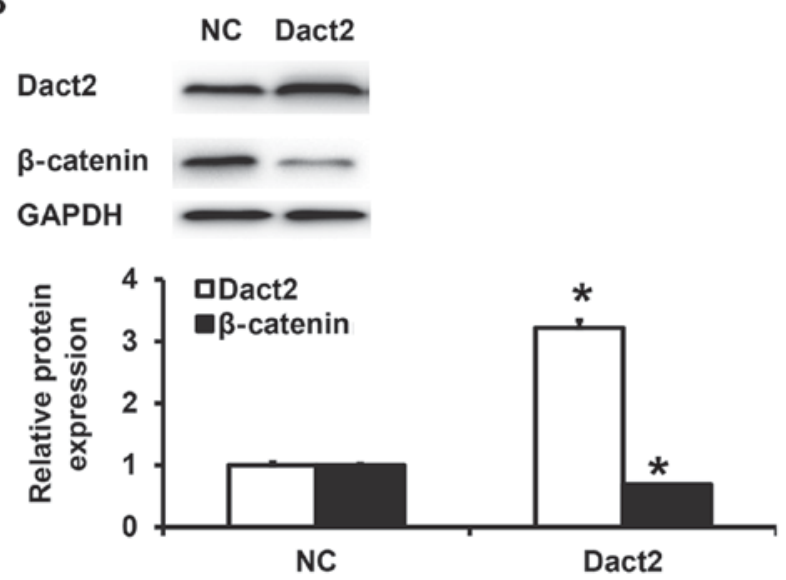

Figure 4. Effect of miR-214 on the expression of Dact2 and its downstream protein $\beta$-catenin. (A) Mixed gastric adenocarcinoma type MKN28 cells were transfected with NC, miR-214 mimics or miR-214 inhibitor before determination of Dact 2 and $\beta$-catenin protein expression by western blotting. (B) Mixed gastric adenocarcinoma type MKN28 cells were transfected with $\mathrm{NC}$ or Dact 2 before determination of Dact 2 and $\beta$-catenin protein expression by western blotting. " $\mathrm{P}<0.05$ compared with $\mathrm{NC}$ group. NC, negative control; miRNA, microRNA; Dact2, dapper, antagonist of $\beta$-catenin 2 .

to other solid tumors, the proliferation and metastasis of gastric cancer cells are regulated by multiple genes and multiple factors $(22,23)$. miRNA has powerful post-transcriptional regulation function and a wide application prospect in tumor therapy. It is reported that many miRNA molecules are expressed abnormally in gastric cancer cells and play important roles in the occurrence and development of gastric cancer (24).

Wnt/ $\beta$-catenin signaling pathway is abnormally activated in many tumors, and promotes tumor formation, maintenance, invasion, metastasis and drug resistance (25). As an important negative regulator of $\mathrm{Wnt} / \beta$-catenin signaling pathway, Dact2 has become a focus among researchers (26). The deletion of Dact2 leads to the activation of Wnt/ $\beta$-catenin signaling pathway, and facilitates the occurrence and development of colon cancer, esophageal cancer and liver cancer. Studies show that the deletion of Dact2 is related to the methylation of promoter region. For example, methylation of the Dact2 gene promoter leads to the silencing of Dact 2 gene, and promotes epithelial mesenchymal transition and cytoskeletal rearrangement in 
A
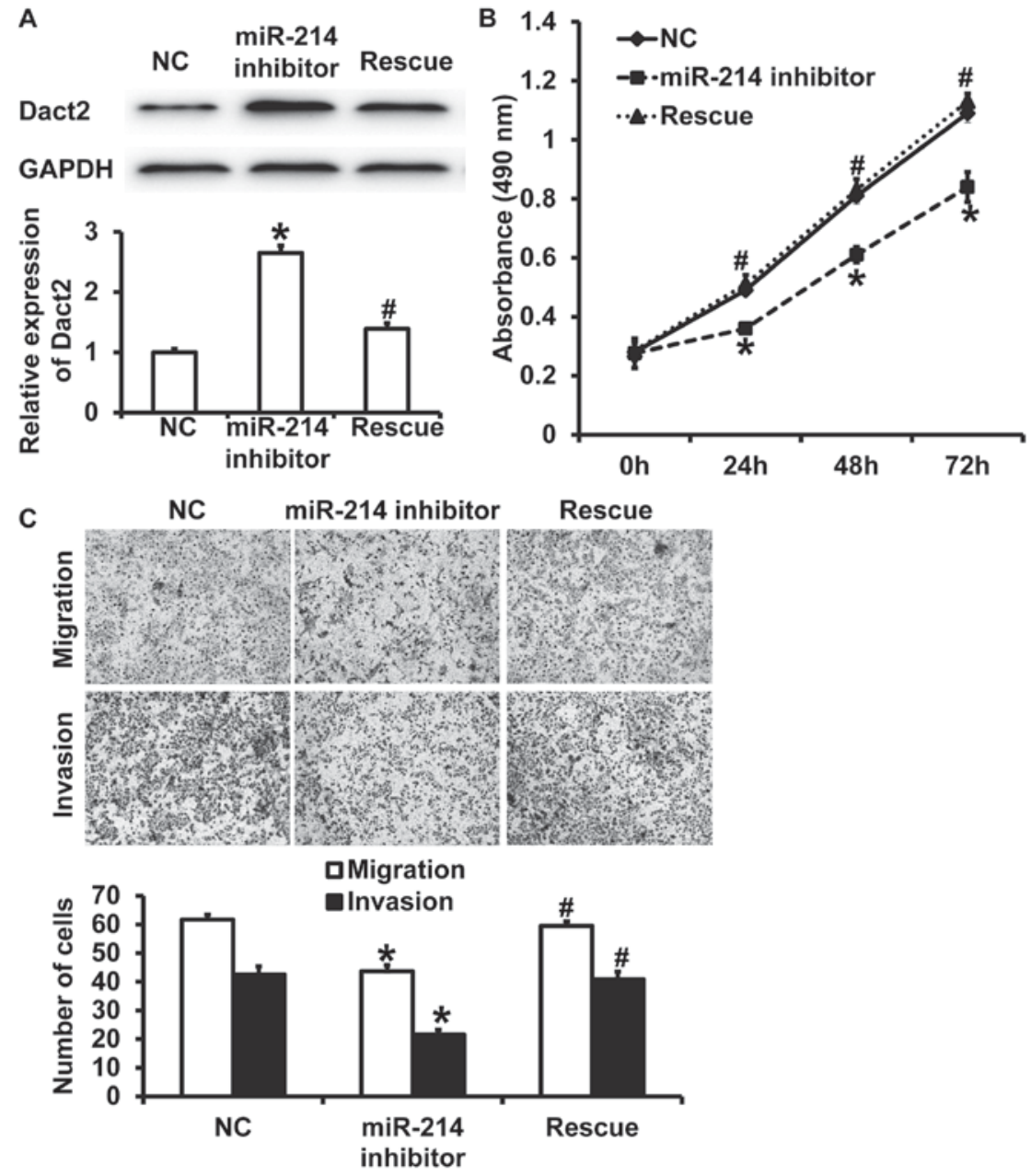

Figure 5. Effect of Dact2 expression regulated by miR-214 on the proliferation, migration and invasion of mixed gastric adenocarcinoma type MKN28 cells. (A) Effect of inhibition and rescue of miR-214 expression on the expression of Dact2 protein determined by western blotting. (B) Effect of inhibition and rescue of miR-214 expression on the proliferation of mixed gastric adenocarcinoma type MKN28 cells determined by CCK- 8 assay. (C) Effect of inhibition and rescue of miR-214 expression on the migration and invasion of mixed gastric adenocarcinoma type MKN28 cells determined by Transwell assay (magnification, x100). Statistical comparisons among the NC, miR-214 inhibitor and Rescue groups were performed using ANOVA and Dunnett's test as a post-hoc test. Statistical analysis showed no significant difference between Rescue and NC groups, but miR-214 was significantly different from Rescue and NC groups. ${ }^{*} \mathrm{P}<0.05$ compared with NC group; ${ }^{*} \mathrm{P}<0.05$ compared with miR-214 inhibitor group. NC, negative control; miRNA, microRNA; Dact 2 , dapper, antagonist of $\beta$-catenin 2; CCK-8, Cell-Counting kit.

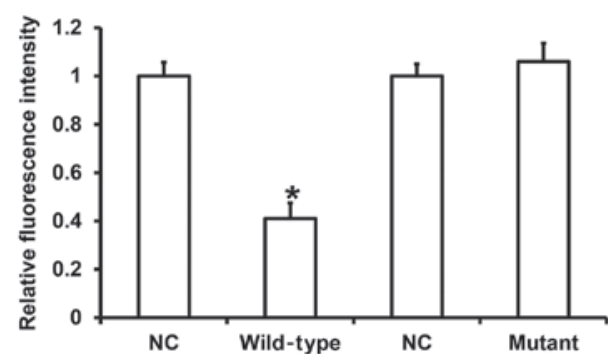

Figure 6.Identification of interaction between miR-214 and Dact2 mRNA using dual luciferase reporter assay. WT and mutant seeding regions of miR-214 in 3'-UTR of DACT2 gene were chemically synthesized before adding Spe-1 and HindIII restriction sites, and then cloned into pMIR-REPORT luciferase reporter plasmids $(0.5 \mu \mathrm{g})$ with WT or mutant 3'-UTR DNA sequences, which were transfected together with miR-214 mimics into HEK293T cells. Following incubation for $24 \mathrm{~h}$, cells were processed using dual luciferase reporter assay kit according to the manufacturer's manual, and fluorescence intensity was determined by GloMax 20/20 luminometer. Fluorescence values of each group of were measured using renilla fluorescence activity as internal reference. ${ }^{*} \mathrm{P}<0.05$ compared with respective $\mathrm{NC}$ group. $\mathrm{NC}$, negative control; WT, wild-type; miRNA, microRNA; Dact2, dapper, antagonist of $\beta$-catenin 2; UTR, untranslated region. breast cancer (27). Moreover, aberrant methylation of Dact2 promoter in squamous cell carcinoma of esophagus is the key reason for silenced expression of Dact2, and this ultimately promotes the invasion and metastasis of squamous cell carcinoma (28). However, promoter methylation does not necessarily exist in tumor tissues with downregulated Dact 2 expression, suggesting that Dact2 has other regulatory mechanisms.

miRNA molecules are key regulators of mRNA at posttranscriptional levels, and they are almost involved in all physiological and pathological activities of the body. Studies have shown that a variety of miRNA molecules have been involved in the regulation of $\mathrm{Wnt} / \beta$-catenin signaling pathway. For example, Liu et al discover that miR-155 promotes the proliferation and metastasis of SW-480 cells by regulating Wnt/ $\beta$-catenin signaling pathway (29). Wei et al find that miR-638 inhibits the metastasis of cervical cancer cells by regulating Wnt/ $\beta$-catenin signaling pathway (30). The discovery of these miRNA molecules 
provides new targets for the regulation of $\mathrm{Wnt} / \beta$-catenin signaling pathway. In the present study, we use bioinformatics to predict that miR-214 may regulate Dact2 gene. Using qRT-PCR, we identified upregulated expression of miR-214 in gastric cancer tissues, which is positively related with clinical staging and lymphatic metastasis. Moreover, expression of Dact2 gene is downregulated, and negatively correlated with clinical staging and lymphatic metastasis. Cellular functional experiments show that miR-214, as an oncogene, promotes the proliferation, migration and invasion of gastric cancer cells. By contrast, Dact2 acts as a tumor-suppressor gene that inhibits the proliferation, migration and invasion of gastric cancer cells. These results demonstrate that the function and expression of miR-214 are reversely related with Dact2, suggesting that miR-214 may exert its biological functions via Dact2. Western blotting shows that miR-214 regulates the expression of Dact2. Furthermore, rescue experiments demonstrate that Dact2 inhibits the tumor-promoting effect of miR-214. Indeed, dual luciferase reporter assay shows that miR-214 directly binds with the 3'-UTR of Dact2 mRNA.

In conclusion, miR-214 downregulates the expression of Dact2 gene, activates Wnt/ $\beta$-catenin signaling pathway, and promotes the proliferation, migration and invasion of gastric cancer. Therefore, miR-214 is a potential molecular therapeutic target and biomarker for gastric cancer. In our future studies, we will investigate the correlation between the expression of miR-214 and Dact2 in tissues, and test the function and mechanism of action of miR-214 at animal level.

\section{Acknowledgements}

The authors would like to thank their department and research team for their help and dedication.

\section{Funding}

Project of Heilongjiang Provincial Health Bureau (grant no. 2011-094).

\section{Availability of data and materials}

The datasets used and/or analyzed during the current study are available from the corresponding author on reasonable request.

\section{Authors' contributions}

LZ designed the study. WF, YF and SG were responsible for performing experiments. LZ and WF analyzed the data. All authors collaborated to interpret results and develop the manuscript. The final version of the manuscript has been read and approved by all authors.

\section{Ethics approval and consent to participate}

All procedures performed in the current study were approved by the Ethics Committee of Harbin Medical University. Written informed consent was obtained from all patients or their families.

\section{Patient consent for publication}

Written informed consents for publication of any associated data and accompanying images were obtained from all patients or their parents, guardians or next of kin.

\section{Competing interests}

The authors declare that they have no competing interests.

\section{References}

1. Wei TT, Wang LL, Yin JR, Liu YT, Qin BD, Li JY, Yin X, Zhou L and Zhong RQ: Relationship between red blood cell distribution width, bilirubin, and clinical characteristics of patients with gastric cancer. Int J Lab Hematol 39: 497-501, 2017.

2. Choi HI, Choi JP, Seo J, Kim BJ, Rho M, Han JK and Kim JG: Helicobacter pylori-derived extracellular vesicles increased in the gastric juices of gastric adenocarcinoma patients and induced inflammation mainly via specific targeting of gastric epithelial cells. Exp Mol Med 49: e330, 2017.

3. Zhuo C, Ying M, Lin R, Wu X, Guan S and Yang C: Negative lymph node count is a significant prognostic factor in patient with stage IV gastric cancer after palliative gastrectomy. Oncotarget 8 : 71197-71205, 2017.

4. Singh P, Toom S and Huang Y: Anti-claudin 18.2 antibody as new targeted therapy for advanced gastric cancer. J Hematol Oncol 10: 105, 2017.

5. Lin XL, Xu Q, Tang L, Sun L, Han T, Wang LW and Xiao XY: Regorafenib inhibited gastric cancer cells growth and invasion via CXCR4 activated Wnt pathway. PLoS One 12: e0177335, 2017.

6. Arias Sosa LA, Cuspoca Orduz AF and Bernal Gómez BM: Deregulation of microRNAs in gastric cancer: Up regulation by miR-21 and miR-106. Rev Gastroenterol Peru 37: 65-70, 2017 (In Spanish).

7. Komsky-Elbaz A and Roth Z: Effect of the herbicide atrazine and its metabolite DACT on bovine sperm quality. Reprod Toxicol 67: 15-25, 2017

8. Schubert FR, Sobreira DR, Janousek RG, Alvares LE and Dietrich S: Dact genes are chordate specific regulators at the intersection of Wnt and Tgf- $\beta$ signaling pathways. BMC Evol Biol 14: 157, 2014.

9. Sensiate LA, Sobreira DR, Da Veiga FC, Peterlini DJ, Pedrosa AV, Rirsch T, Joazeiro PP, Schubert FR, Collares-Buzato CB, Xavier-Neto J, et al: Dact gene expression profiles suggest a role for this gene family in integrating Wnt and TGF- $\beta$ signaling pathways during chicken limb development. Dev Dyn 243: 428-439, 2014.

10. Wang S, Dong Y, Zhang Y, Wang X, Xu L, Yang S, Li X, Dong H, $\mathrm{Xu} \mathrm{L}, \mathrm{Su} \mathrm{L}$, et al: DACT2 is a functional tumor suppressor through inhibiting Wnt/ $\beta$-catenin pathway and associated with poor survival in colon cancer. Oncogene 34: 2575-2585, 2015.

11. Schussel JL, Kalinke LP, Sassi LM, de Oliveira BV, Pedruzzi PA, Olandoski M, Alvares LE, Garlet GP and Trevilatto PC: Expression and epigenetic regulation of DACT1 and DACT2 in oral squamous cell carcinoma. Cancer Biomark 15: 11-17, 2015.

12. Yu Y, Yan W, Liu X, Jia Y, Cao B, Yu Y, Lv Y, Brock MV, Herman JG, Licchesi J, et al: DACT2 is frequently methylated in human gastric cancer and methylation of DACT2 activated Wnt signaling. Am J Cancer Res 4: 710-724, 2014.

13. Jia Y, Yang Y, Brock MV, Zhan Q, Herman JG and Guo M: Epigenetic regulation of DACT2, a key component of the Wnt signalling pathway in human lung cancer. J Pathol 230: 194-204, 2013.

14. Zhang X, Yang Y, Liu X, Herman JG, Brock MV, Licchesi JD, Yue W, Pei X and Guo M: Epigenetic regulation of the Wnt signaling inhibitor DACT2 in human hepatocellular carcinoma. Epigenetics 8: 373-382, 2013.

15. Manne RK, Agrawal Y, Bargale A, Patel A, Paul D, Gupta NA, Rapole S, Seshadri V, Subramanyam D, Shetty P and Santra MK: A microRNA/Ubiquitin ligase feedback loop regulates slug-mediated invasion in breast cancer. Neoplasia 19: 483-495, 2017.

16. Michael JV, Wurtzel JGT, Mao GF, Rao AK, Kolpakov MA, Sabri A, Hoffman NE, Rajan S, Tomar D, Madesh M, et al: Platelet microparticles infiltrating solid tumors transfer miRNAs that suppress tumor growth. Blood 130: 567-580, 2017. 
17. Xie M, Dart DA, Guo T, Xing XF, Cheng XJ, Du H, Jiang WG, Wen XZ and Ji JF: MicroRNA-1 acts as a tumor suppressor microRNA by inhibiting angiogenesis-related growth factors in human gastric cancer. Gastric Cancer 21: 41-54, 2018.

18. Li M, Gu K, Liu W, Xie X and Huang X: MicroRNA-200c as a prognostic and sensitivity marker for platinum chemotherapy in advanced gastric cancer. Oncotarget 8: 51190-51199, 2017.

19. Yang X, Zhao Q, Yin H, Lei X and Gan R: MiR-33b-5p sensitizes gastric cancer cells to chemotherapy drugs via inhibiting HMGA2 expression. J Drug Target 25: 653-660, 2017.

20. Shen X, Pan B, Zhou H, Liu L, Lv T, Zhu J, Huang X and Tian J: Differentiation of mesenchymal stem cells into cardiomyocytes is regulated by miRNA-1-2 via WNT signaling pathway. J Biomed Sci 24: 29, 2017.

21. Capes-Davis A, Theodosopoulos G, Atkin I, Drexler HG, Kohara A, MacLeod RA, Masters JR, Nakamura Y, Reid YA, Reddel RR and Freshney RI: Check your cultures! A list of cross-contaminated or misidentified cell lines. Int J Cancer 127: $1-8,2010$.

22. Zeng XQ, Wang J and Chen SY: Methylation modification in gastric cancer and approaches to targeted epigenetic therapy (Review). Int J Oncol 50: 1921-1933, 2017.

23. Hayakawa Y, Fox JG and Wang TC: The origins of gastric cancer from gastric stem cells: Lessons from mouse models. Cell Mol Gastroenterol Hepatol 3: 331-338, 2017.

24. Jafari N and Abediankenari S: MicroRNA-34 dysregulation in gastric cancer and gastric cancer stem cell. Tumour Biol 39: 1010428317701652,2017
25. Huang M, Chen C, Geng J, Han D, Wang T, Xie T, Wang L, Wang Y, Wang C, Lei Z and Chu X: Targeting KDM1A attenuates Wnt/ $\beta$-catenin signaling pathway to eliminate sorafenib-resistant stem-like cells in hepatocellular carcinoma. Cancer Lett 398: 12-21, 2017.

26. Guo YL, Shan BE, Guo W, Dong ZM, Zhou Z, Shen SP, Guo X, Liang J and Kuang G: Aberrant methylation of DACT1 and DACT2 are associated with tumor progression and poor prognosis in esophageal squamous cell carcinoma. J Biomed Sci 24: 6, 2017.

27. Xiang T, Fan Y, Li C, Li L, Ying Y, Mu J, Peng W, Feng Y, Oberst M, Kelly K, et al: DACT2 silencing by promoter CpG methylation disrupts its regulation of epithelial-to-mesenchymal transition and cytoskeleton reorganization in breast cancer cells. Oncotarget 7: 70924-70935, 2016.

28. Zhang M, Linghu E, Zhan Q, He T, Cao B, Brock MV, Herman JG, Xiang R and Guo M: Methylation of DACT2 accelerates esophageal cancer development by activating Wnt signaling. Oncotarget 7: 17957-17969, 2016.

29. Liu N, Jiang F, Han XY, Li M, Chen WJ, Liu QC, Liao CX and Lv YF: MiRNA-155 promotes the invasion of colorectal cancer SW-480 cells through regulating the Wnt $/ \beta$-catenin. Eur Rev Med Pharmacol Sci 22: 101-109, 2018.

30. Wei H, Zhang JJ and Tang QL: MiR-638 inhibits cervical cancer metastasis through $\mathrm{Wnt} / \beta$-catenin signaling pathway and correlates with prognosis of cervical cancer patients. Eur Rev Med Pharmacol Sci 21: 5587-5593, 2017. 